\title{
ЭКСПЕРТНО-КРИМИНАЛИСТИЧЕСКАЯ ДЕЯТЕЛЬНОСТЬ ПОЛИЦИИ
}

Савченко О.A.

\section{ОСНОВЫ КРИМИНАЛИСТИЧЕСКОГО ИССЛЕДОВАНИЯ КОМПЬЮТЕРНОЙ ИНФОРМАЦИИ}

Аннотация: Объектом исследования является деятельность по раскрытию и расследованию преступлений, совершенных в сфере информационно-телекоммуникационных технологий. Предметом исследования являются основные признаки и свойства компьютерной информации как объекта криминалистического исследования. Автор производит анализ концепций природы компьютерной информации и процесса ее генерации, перечисляются основные фрормы ее представления. Указываются методы работы с компьютерной информацией и следами киберпреступлений. Компьютерная информация как предмет криминалистического исследования рассматривается в качестве предмета преступного посягательства, орудия совершения преступления, доказательства и одного из видов следов преступлений в сфере компьютерной информации. В работе применены общенаучные и частнонаучные методы исследования, такие как метод аналогии, дедукции, сравнения, системного анализа, а также приемы фрормальной логики, прогнозирования и межпарадигмальный подход. Криминалистическое исследование компьютерной информации предусмотрено в подразделе судебных экспертиз компьютерной техники и данных раздела криминалистической техники. Тем не менее, компьютерная информация и технологии находят свое применение и в других разделах науки: ее основах, тактике и методике. Таким образом, научная новизна настоящего исследования заключается в том, что необходимо теоретическое обоснование и закрепление применения информационных технологий в процессе раскрытия и расследования преступлений, другими словами, эмпирических знаний, в качестве основ криминалистического исследования компьютерной информации. В результате исследования сформулированы понятия информации в сфрере информационно-телекоммуникационных технологий, следов преступлений в сфере компьютерной информации. Предлагаются направления развития технико-криминалистических средств, используемых в процессе раскрытия и расследования преступлений в сфере информационнотелекоммуникационных технологий. Результаты исследования могут быть применены в формировании теории науки криминалистики, в процессе расследования преступлений в сфрере компьютерной информации и производства судебных экспертиз в данной области, а также в процессе обучения студентов, магистрантов, аспирантов в рамках дисциплины криминалистики.

Ключевые слова: Компьютерная информация, информационные телекоммуникационные технологии, технико-криминалистические средства, следы кибер- 
преступлений, расследование, кибернетический метод, фрорма представления инфрормации, криминалистическое исследование, материальная природа, сфера компьютерной информации.

Review: The research object is investigation and detection of crimes committed in the sphere of information and telecommunication technologies. The research subject includes the main features of computer information as an object of forensic processing. The author analyzes the concepts of the nature of computer information and the process of its generating, and enumerates the main forms of its presenting. The author outlines the methods of work with computer information and traces of cybercrimes. Computer information as an object of forensic processing is considered as an object of criminal infringement, an instrument of crime, an evidence, and one of the forms of traces of cybercrimes. The author applies general and specific scientific research methods, including analogy, deduction, comparison, the system analysis, and the methods of formal logic, prognostication, and the interparadigmatic approach. Forensic processing of computer information is provided in the subsection of digital forensic services and the section of criminal investigation technique. At the same time, computer information and technologies are applied in other branches of the science: its fundamentals, tactics, and methodology. Thus the scientific novelty of the research lies in the conclusion about the need for a theoretical explanation and consolidation of application of information technologies in the process of detection and investigation of crimes, in other words, empirical knowledge, as the fundamentals of forensic processing of computer information. The author formulates the concepts of information in the sphere of telecommunication technologies, and the traces of crimes in the sphere of computer information. The author suggests the directions of development of forensic instruments used in the process of investigation and detection of cybercrimes. The research results can be applied for forming the theory of criminalistics, in investigation and detection of crimes and forensic expertise in the sphere of computer information, for teaching students, undergraduates and postgraduates in the criminalistics discipline.

Keywords: Form of presentation of information, cybernetic method, investigation, traces of cybercrimes, forensic instruments, information and telecommunication technologies, computer information, forensic processing, material nature, sphere of computer information.

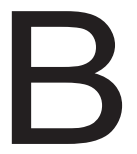

рамках инфрормационной концепции, в качестве предмета криминалистики принято рассматривать информационно-познавательную структуру деятельности по раскрытию и расследованию преступлений [7, стр. 20]. В число основных объектов криминалистического исследования входят элементы механизма преступления, а именно источники криминалистически значимой информации. К дан- ным источникам, в том числе, относятся носители компьютерной информации.

Компьютерная информация представляет собой, во-первых, сведения и данные вне формы их представления, воспринимаемые компьютерной вычислительной техникой и являющиеся предметом сореры информационно-телекоммуникационных технологий. Во-вторых, компьютерная информация является 
формой представления видов родового понятия информации в процесce ее обработки средствами вычислительной техники. Ярким примером в рамках второго определения является мультимедийная информация, представляющая результат обработки различных видов информации (аудио-, видеоинформация) посредством информационно-телекоммуникационных технологий. В-третьих, компьютерной информацией является сам продукт высокотехнологичного процесса работы средств вычислительной техники.

В терминологическом словаре судебной компьютерной экспертизы под редакцией О.В. Тушкановой дано несколько определений информации, среди которых можно выделить такое, согласно которому под информацией понимаются сведения о лицах, предметах, фрактах, событиях, явлениях и процессах независимо от формы их представления, а также сведения, воспринимаемые человеком и (или) специальным устройством как отражение фактов материального или духовного мира в процессе коммуникации [15, стр. 52]. Данное определение имеет расширительное толкование дефиниции информации, и, в том числе, охватывает понятие информации, воспринимаемой компьютерной техникой, другими словами - компьютерной информации.

Таким образом, компьютерная информация - форма информации, особенность которой заключается в принадлежности сорере информационно-телекоммуникационных технологий - вида информационных технологий. Информационные тех- нологии представляют собой совокупность средств, устройств и методов по их применению, предназначенных для обработки (получения, изъятия, сохранения, модификации, создания) информации. Внедрение информационных технологий в процесс криминалистического исследования является одним из приоритетных направлений развития науки криминалистики.

Помимо информационных технологий как процедуры исследования информации, существует и специальный метод. Кибернетический метод относится к общенаучным методам исследования и применяется в науке криминалистики, в частности, в целях расследования преступлений, создания компьютерных информационных моделей и учетов, исследования компьютерной информации в качестве доказательства, предмета киберпреступлений.

Исследование природы компьютерной информации следует начинать с изучения процесса ее генерации, источника. Информация как отражение материального мира, неразрывно связана с материей и энергией [17, стр. 5]. Компьютерная информация, в свою очередь, также связана с материальным объектом - вычислительной техникой. В связи с многообразием видов последней, невозможно говорить о природе компьютерной информации только как об электронной. В форме сигналов, дискретной или непрерывной, информация передается по беспроводным сетям, может быть переводимой в аналоговую, цифровую, электронную формы. Цифровой сиг- 
нал относится к дискретным и представлен в виде импульсных двоичных последовательностей [3, стр. 49]. С.Г. Басиладзе полагает, что сигнал является не формой, а носителем информации [1, стр. 310]. Тем не менее, компьютерная информация, передаваемая в форме сигнала (динамичная составляющая), может быть записана на устройство или зарегистрирована в протоколе системы в виде кода (статичная составляющая). Обе фрормы (сигнал, импульс) имеют физическую, материальную природу.

В области исследования доказательств, следов преступлений криминалистика имеет дело с объектами материального мира, неотъемлемой принадлежностью которых является информация. В словаре по криминалистике указывается такое понятия как информативность следа, под которой подразумевается способность следа сохранять и передавать содержащуюся в нем информацию о следообразующем объекте и механизме следообразования [13, стр. 105]. В соответствии с данным определением, информативная составляющая следа, тем более в сфере информационно-телекоммуникационных технологий, имеет как минимум два признака: об объекте, оставившим данный след, и об особенностях механизма следообразования. Вместе с изъятием предмета эксперт получает набор информации, из которого необходимо выделить криминалистически значимую информацию одно из основных базовых понятий науки криминалистики. Фактически, на первых стадиях - отражения, обнаружения и фиксации, следы пред- ставляют собой не что иное, как данные, и только на последующих стадиях их обработки данные переходят в разряд информации. В рамках разработанной Е.Г. Белоглазовым системы управления оперативно-розыскной информацией употребляется термин информационных следов преступлений как исходной информации об исследуемых объектах [2, стр. 4]. Следы в сорере компьютерной информации (компьютерные либо информационные следы) представляют собой разновидность компьютерной информации, изменение ее нормальной структуры вследствие совершения преступления. Тогда как сами преступления в сорере компьютерной информации, или киберпреступления, представляют собой вид инфрормационных преступлений. В юридической литературе имеется определение компьютерных преступлений, которыми считаются «информационные преступления, предметом посягательства или средством совершения которых является информация, введенная в оборот посредством компьютерных информационных технологий [9, стр. 9].

E.C. Лапин также делает вывод о том, что следом, оставленным в информационно-телекоммуникационной среде, следует считать саму компьютерную информацию [8, стр. 80]. Ряд ученых (А.М. Багмет, С.Ю. Скобелин) в области криминалистической техники подразумевают под информацией, содержащейся на электронных устройствах, цифровые (электронные) следы [14, стр. 213]. Н.Н. Федотов под компьютерным следом подразумевает запись в logфайле [16, стр. 17], и указывает пе- 
речень средств, необходимых для обнаружения данного следа, среди которых можно отметить жесткий диск, контроллеры, программное обеспечение для просмотра содержимого фрайла, операционную систему и драйверы, аппаратные средства ввода-вывода и иные технические средства. О.В. Полещук, Г.М. Шаповалова называют следы, оставляемые вследствие совершения преступления в компьютерной системе, информационными [11, стр. 15]. Понятие «информационные следы» шире по своему содержанию, так как им может быть любое изменение обстановки информационного характера вследствие совершения информационного преступления. Целесообразнее данные следы определять как «следы в сфрере компьютерной информации», «следы в сорере информационно-телекоммуникационных технологий» или «компьютерные следы», подразумевая под понятием «компьютерный» соответствие настоящему уровню развития техники и отнесение данного вида следов или информации к предмету компьютерных инфрормационных технологий.

Следы в сорере компьютерной информации, как следствие изменения обычного состояния компьютерной системы или информационной среды в результате совершения либо попытки совершения киберпреступления, по мнению В.В. Маркова, В.В. Тулупова, представляют собой изменение компьютерных данных на фризическом уровне под влиянием преступной деятельности, имеющих соответствующие следы на логическом и семантиче- ском уровне их представления [12, стр. 120]. Процесс образования компьютерного следа, в узком смысле, по мнению Н.А. Зигура, А.В. Кудрявцевой, вызывается программами [4, стр. 21]. В широком смысле данный след образуется в результате модификации компьютерной информации вследствие воздействия на нее процесса либо явления, осуществление которых возможно в сфере информационно-телекоммуникационных технологий (программы, компьютерные вирусы, сигналы электро-магнитной природы и другие факторы воздействия).

Следовая картина преступления в сорере информационно-телекоммуникационных технологий представлена следующими группами следов: «традиционными» следами с точки зрения трасологии и следами в сфрере обработки компьютерной информации. Первая группа включает следы рук, орудий и устройств, то есть все те следы, которые образованы в результате внешнего механического воздействия. Ко второй группе относятся следы, образованные в сфрере компьютерной информации и информационно-телекоммуникационных технологий в результате модификации компьютерной информации. Для целей криминалистического исследования следов в сорере компьютерной информации важно установить их сущностное содержание, в отношении которого существует две концепции: материальная и нематериальная (идеальная). Д.А. Ефремов, один из представителей материальной концепций, под следом подразумевает информационный отпеча- 
ток, и относит компьютерные следы к материальным в силу технических процессов их образования [5, стр. 99]. Представители полярной точки зрения полагают, что следы в сфрере компьютерной информации имеют нематериальную природу. А.В. Нарижный, А.Х. - А. Пихов подразделяют следы, образованные при совершении киберпреступления, на материальные следы и виртуальные, которые являются, по мнению авторов, идеальными следами [10, стр. 28-29]. А.А. Косынкин также считает, что следы компьютерных преступлений являются нематериальными, информационными следами, и относятся к информационной среде, которую автор определил как информационную компьютерную среду [6, стр. 12].

Доказательство материальной концепции компьютерной информации основано на положениях науки информатики, кибернетики и, наконец, на принципах архитектуры компьютерной техники и следующей из нее природы компьютерной информации. Сигнал, машинный код - категории фризического свойства, материальной основы. Компьютерные устройства - продукт техники, принцип работы которой основан на программном управлении. Виртуальный характер компьютерной информации, который является центральным положением в рамках нематериальной концепции, - следствие и необходимость в визуализации данных для удобства восприятия их человеком. Структура компьютерной информации, таким образом, представлена двумя составляющими: 1) содержательной - непосред- ственно сама компьютерная информация в форме сигнала или в виде кода, материальной природы, и 2) интерактивной - своеобразной надстройкой компьютерной информации, которая может быть отнесена к идеальной природе. Виртуальное представление компьютерной информации (ее интерактивная, визуализированная форма) является идеальной моделью компьютерной информации, тогда как последняя, представленная в форме сигнала - объект материальной природы. Из чего можно сделать вывод, что компьютерной может называться информация, воспринимаемая аппаратным комплексом инфрормационно-телекоммуникационных технологий в виде своей содержательной составляющей, тогда как, например, распечатка того же кода в виде символов посредством печатного устройства уже не является компьютерной информацией, а ее абстрактной моделью. Учитывая изложенное, компьютерная информация, как форма представления родового понятия информации, и следы в сорере информационнотелекоммуникационных технологий имеют материальную основу. И материальная, и идеальная (нематериальная) концепции находят свое выражение в философии информации, предметом исследования которой, в том числе, является природа родового понятия информации.

Компьютерная информация может быть не только объектом криминалистического исследования, но и средством, применяемым в криминалистической методике, тактике и криминалистической технике. В 
разделе криминалистической тактики при производстве следственных действий компьютерная техника используется как средство фиксации получаемой информации. То есть, посредством тактики реализуется применение технико-криминалистических средств. Одновременно, в рамках назначения экспертиз как процессуального действия, компьютерная информация и ее материальные носители становятся объектом криминалистического исследования информационно-технической экспертизы. В области криминалистической техники нет отдельного раздела, посвященного изучению информации, однако, компьютерная техника применяется при исследовании документов, построения различного рода моделей, в криминалистических учетах. С точки зрения положений уголовно-процессуального права и теории криминалистики, компьютерная информация может быть представлена в виде электронного документа, признаваемого доказательством. В разделе криминалистической методики используются частные методики расследования преступлений в сорере компьютерной информации, компьютерные методы расследования, компьютерное моделирование. Отдельными службами в их правоохранительной деятельности используются технологии изъятия информации, контроля и записи информации.

Вышеперечисленные примеры подтверждаются многолетней практикой применения компьютерной техники в процессе раскрытия и расследования преступлений, что, в свою очередь, как эмпирическое знание претендует на научное обоснование и теоретическое закрепление результатов данного применения. Таким образом, в целях развития теории и практики криминалистического исследования компьютерной информации, необходимо научное закрепление его основ и таких положений, как: 1) понятие компьютерной информации, соответствующее общенаучным категориям, законодательству в области информационно-телекоммуникационных технологий и сложившемуся криминалистическому знанию; 2) понятие следов преступлений в сорере информационно-коммуникационных технологий как модификации компьютерной информации в результате преступного воздействия; 3) понятие материальных оснований компьютерной формы представления информации; 4) понятие относимого к виду техникокриминалистических средств программного обеспечения как структурного элемента криминалистических информационных технологий.

В соответствии с концепциями формирования научного знания, можно выделить два основных пути развития криминалистического знания в области компьютерных информационных технологий: 1) дальнейшее накопление эмпирического знания и последующее научное обоснование его результатов как следствие применение частных методик и рекомендаций; 2) теоретическое офрормление и закрепление в основах криминалистической техники, тактики и методики частной теории о криминалистических информаци- 
онных технологиях и формирование практики их применения в соответствии с данными научными положениями. Анализ научных работ и практики расследования преступлений позволяет сделать вывод, что эволюция криминалистического знания о компьютерной информации происходит в соответствии с первым вышеуказанным направлени- ем. Данное развитие представляет собой постепенное накопление теоретического материала на основе эмпирики, тщательно соотносимого с общим вектором развития мысли на всех уровнях научного знания, в настоящее время достаточного для формирования основ криминалистического исследования компьютерной информации.

\section{Библиография:}

1. Басиладзе С.Г. Инфология-сигнал, состояния, данные, информация. Второе дополненное издание. М.: Эдитус, 2015. - 358 с.

2. Белоглазов Е.Г. Информационные технологии и аналитические модели криминальных процессов и явлений: Монография. М.: Московский университет МВД России, 2005. $210 \mathrm{c}$.

3. Гайдамакин А.А., Горев А.И., Косоротов А.П., Чуянов А.Г. Информационная безопасность в органах внутренних дел и применение информационных технологий в борьбе с преступностью. Омск: Омская академия МВД России, 2010 г. - 740 с.

4. Зигура Н.А., Кудрявцева А.В. Компьютерная информация как вид доказательств в уголовном процессе России: Монография. М.: Юрлитинформ, 2011 г. - 176 с.

5. Ефремов Д.А. Научные и правовые основы использования информации при расследовании преступлений: монографрия. М.: Юрлитинформ, 2014. - 168 с.

6. Косынкин А.А. Преодоление противодействия расследованию преступлений в сфере компьютерной информации: монограффия. М.: Юрлитинформ, 2013. - 216 с.

7. Криминалистика: информационные технологии доказывания. Учебник для вузов / под ред. В.Я. Колдина. М.: Зерцало-М, 2007. - 752 с.

8. Лапин Е.С. Философия криминалистики: учебное пособие. Саратов: «Научная книга», 2016. - $146 \mathrm{c}$.

9. Морозов В.К., Остроушко А.В. Методика расследования информационных преступлений, предметом посягательства которых является охраняемая государством информация, включенная в оборот посредством компьютерных информационных технологий: учеб. пособие. М.: Полиграф-Информм, 2009. - 152 с.

10. Нарижный А.В., Пихов А.Х. - А. Использование специальных познаний при раскрытии и расследовании преступлений в сфере высоких технологий: учебно-практическое пособие. Краснодар: Краснодарский университет МВД России, 2014. - 62 с.

11. Полещук О.В., Шаповалова Г.М. Криминалистическое исследование следов при расследовании компьютерных преступлений: Монография. Владивосток: Изд-во Дальневосточного Университета, 2006 г. - 157 с.

12. Противодействие преступлениям в сфрере информационных технологий. Материалы международной научно-практической конференции 23.05.2013 г. Белгород: Белгородский юридический институт МВД России, 2013 г. - 204 с.

13. Словарь по криминалистике. 1250 терминов и определений / авт. - сост. А.М. Багмет и др.; под ред. А.И. Бастрыкина. - М.: ЮНИТИ-ДАНА, 2015. - 383 с.

14. Технико-криминалистическое сопровождение расследования преступлений: учеб. пособие / под ред. канд. юр. наук А.М. Багмета. - М.: Юрлитинформ, 2016. - 256 с. 
15. Тушканова О.В. Терминологический справочник судебной компьютерной экспертизы: справочное пособие. М.: МАКС Пресс, 2005 г. - 260 с.

16. Федотов Н.Н. Форензика-компьютерная криминалистика. М.: Юридический мир, 2007. $-360 \mathrm{c}$.

17. Царев Р.Ю., Прокопенко А.В., Князьков А.Н. Программные и аппаратные средства инфрорматики: учеб. Красноярск: Сибирский федеральный университет, 2015. - 160 с

\section{References (transliterated):}

1. Basiladze S.G. Infologiya-signal, sostoyaniya, dannye, informatsiya. Vtoroe dopolnennoe izdanie. M.: Editus, 2015. - $358 \mathrm{~s}$.

2. Beloglazov E.G. Informatsionnye tekhnologii i analiticheskie modeli kriminal'nykh protsessov i yavlenii: Monografiya. M.: Moskovskii universitet MVD Rossii, 2005. - $210 \mathrm{~s}$.

3. Gaidamakin A.A., Gorev A.I., Kosorotov A.P., Chuyanov A.G. Informatsionnaya bezopasnost' $v$ organakh vnutrennikh del i primenenie informatsionnykh tekhnologii $v$ bor'be $s$ prestupnost'yu. Omsk: Omskaya akademiya MVD Rossii, 2010 g. - 740 s.

4. Zigura N.A., Kudryavtseva A.V. Komp'yuternaya informatsiya kak vid dokazatel'stv v ugolovnom protsesse Rossii: Monografiya. M.: Yurlitinform, 2011 g. - 176 s.

5. Efremov D.A. Nauchnye i pravovye osnovy ispol'zovaniya informatsii pri rassledovanii prestuplenii: monografiya. M.: Yurlitinform, 2014. - $168 \mathrm{~s}$.

6. Kosynkin A.A. Preodolenie protivodeistviya rassledovaniyu prestuplenii v sfere komp'yuternoi informatsii: monografiya. M.: Yurlitinform, 2013. - $216 \mathrm{~s}$.

7. Lapin E.S. Filosofiya kriminalistiki: uchebnoe posobie. Saratov: «Nauchnaya kniga», 2016. $-146 \mathrm{~s}$.

8. Morozov V.K., Ostroushko A.V. Metodika rassledovaniya informatsionnykh prestuplenii, predmetom posyagatel'stva kotorykh yavlyaetsya okhranyaemaya gosudarstvom informatsiya, vklyuchennaya v oborot posredstvom komp'yuternykh informatsionnykh tekhnologii: ucheb. posobie. M.: Poligraf-Informm, 2009. - $152 \mathrm{~s}$.

9. Narizhnyi A.V., Pikhov A.Kh. - A. Ispol'zovanie spetsial'nykh poznanii pri raskrytii i rassledovanii prestuplenii v sfere vysokikh tekhnologii: uchebno-prakticheskoe posobie. Krasnodar: Krasnodarskii universitet MVD Rossii, 2014. - 62 s.

10. Poleshchuk O.V., Shapovalova G.M. Kriminalisticheskoe issledovanie sledov pri rassledovanii komp'yuternykh prestuplenii: Monografiya. Vladivostok: Izd-vo Dal'nevostochnogo Universiteta, 2006 g. $-157 \mathrm{~s}$.

11. Tushkanova O.V. Terminologicheskii spravochnik sudebnoi komp'yuternoi ekspertizy: spravochnoe posobie. M.: MAKS Press, 2005 g. - 260 s.

12. Fedotov N.N. Forenzika-komp'yuternaya kriminalistika. M.: Yuridicheskii mir, 2007. - $360 \mathrm{~s}$.

13. Tsarev R.Yu., Prokopenko A.V., Knyaz'kov A.N. Programmnye i apparatnye sredstva informatiki: ucheb. Krasnoyarsk: Sibirskii federal'nyi universitet, 2015. - $160 \mathrm{~s}$ 